\title{
Maxillary expansion as an interceptive treatment for impacted canines
}

\author{
Abstracted from \\ Baccetti T, Mucedero M, Leonardi M, Cozza P. \\ Interceptive treatment of palatal impaction of maxillary canines with rapid maxillary expansion: \\ a randomized clinical trial. Am J Orthod Dentofacial Orthop 2009; 136: 657-661 \\ Address for correspondence: Tiziano Baccetti, Universita' degli Studi di Firenze, \\ Via del Ponte di Mezzo 46-48, 50127 Firenze, Italy. E-mail: t.baccetti@odonto.unifi.it
}

\section{Question: Does interceptive rapid maxillary expansion improve the eruption rates of palatally displace canines?}

Design This was a randomised controlled trial.

Intervention Patients in the control group received no treatment, whereas the patient treatment group had a rapid maxillary expander soldered to bands placed on the second deciduous molars or the first permanent molars. Activation of the screw was continued until the palatal cusps of the maxillary posterior teeth were in contact with the buccal cusps of the mandibular posterior teeth. Once the required expansion was achieved, the expansion screw was locked in position. After expansion, all patients were retained with the expander in place for 6 months after which the patients wore a retention plate at night for 1 year.

Outcome measure The main outcome was successful or unsuccessful eruption of the maxillary permanent canines.

Results The sample comprised 54 patients (32 in the treatment group and 22 in the control). No statistically significant differences were found for any variable at baseline. The prevalence rates of successful eruption of the maxillary canines were $65.7 \%$ (21 subjects) in the treatment group and $13.6 \%$ (three subjects) in the control. The comparison was statistically significant (chi-square, 12.382; $\mathrm{P}>0.001$ ).

Conclusions The use of rapid maxillary expansion (RME) in the early mixed dentition appears to be an effective procedure to increase the rate of eruption of palatally displaced maxillary canines (PDC) compared with an untreated control group.

\section{Commentary}

Although the incidence of impaction of maxillary permanent canines is cited to be only between $0.2 \%$ and $2.8 \%$, the fact that 80 to $85 \%$ of these teeth impact palatally means that a significant amount of time, effort and expense is required, on the part of the patient and clinician, in order to retrieve and subsequently align these teeth. Thus, any interceptive procedure that could provide early resolution of this situation would be very attractive indeed. Early management of PDC would require a diagnostic technique that is reliable, and needs to be followed by an intervention with a high success rate.

This randomised clinical study investigates both of these demands. Sixty subjects of between 7.6 and 9.6 years in age were recruited and randomly allocated to a treatment group who would receive RME, or to a nontreatment group who were re-evaluated in the early permanent dentition. Despite random allocation, the treatment group consisted of 35 subjects, with only 25 in the nontreatment group. Interestingly, the inclusion criteria included a Class II or Class III tendency, or mild tooth size/ arch size discrepancy. A further inclusion criterion was positive prediction of PDC, derived from the analysis of posteroanterior (PA) cephalometric radiographs according to a method described by Sambataro et al..$^{1}$ It is fair to say that the use of PA cephalograms in orthodontic research and clinical practice is relatively uncommon. Careful attention to radiographic technique and selection of visible landmarks can, however, produce acceptable reliability according to a number of authors. ${ }^{2-6}$ It is worth commenting, though, that screening for potential PDC using this technique in 7-9 year olds would not be widely practised; the most common diagnostic technique is palpation of the developing maxillary canines at around 10 years of age. ${ }^{7}$

The authors state that maxillary expansion has been proposed as an interceptive treatment for impacted canines, as some authors have observed transverse maxillary deficiency in cases of impacted canines. They concede, however, that others have found normal to wide arches in conjunction with PDC. ${ }^{8}$ They comment that the pretreatment maxillary width of the subjects with PDC in this study had no transverse maxillary deficiency at the skeletal level, but did so at the dentoalveolar level.

In this study, the treatment group were expanded with RME until overexpansion was achieved. There were six dropouts, three from each group, comprising $10 \%$ of the sample. The fate of these patients' canines is unknown and not included in the analysis. The results showed that in the treatment group, successful eruption occurred in $65.7 \%$ of the cases, compared with $13.6 \%$ in the nontreatment group. 
The authors concede that the effectiveness of this technique is similar to success rates cited with extraction of deciduous canines alone: at $78 \%,{ }^{9} 62 \%,{ }^{10} 65 \%{ }^{11}$ or, combined with orthodontic treatment with fixed appliances, $75 \% .{ }^{12}$ Thus, although the authors state that RME in the early mixed dentition appears to be effective in improving the eruptive potential of PDC, early detection with screening using PA cephalometry is unlikely to become commonplace and most clinicians will prefer to wait until subjects are 10 years of age, when direct manual palpation of the canines can be performed. If these teeth are not palpable, an early orthodontic referral is advised.

Julian O'Neill

Kettering General Hospital, Rothwell Road, Kettering, Northamptonshire, UK

1. Sambataro S, Baccetti T, Franchi L, Antonini F. Early predictive variables for upper canine impaction as derived from postero-anterior cephalograms. Angle Orthod 2005; 75: $28-34$.

2. Cross DL, McDonald JP. Effect of rapid maxillary expansion on skeletal, dental and nasal structures: a postero-anterior cephalometric study. Eur J Orthod 2000; 22: 519-528.
3. Ishiguro K, Krogman WM, Mazaheri M, Harding RL. A longitudinal study of morphological craniofacial patterns via P-A x-ray headfilms in cleft patients from birth to 6 years of age. Cleft Palate J 1976; 13: 104-126.

4. Athanasiou AE, Tseng CY, Zarrinnia K, Mazaheri M. Frontal cephalometric study of transverse dentofacial growth in children with bilateral cleft of lip, alveolus and palate. / Craniomaxillofacial Surg 1990; 18: 49-54.

5. Cortella S, Shofer FS, Ghafari J. Transverse development of the jaws: norms for the posteroanterior cephalometric analysis. Am J Orthod Dentofacial Orthop 1997; 112: $512-522$.

6. Sandikcioglu M, Hazar S. Skeletal and dental changes after maxillary expansion in the mixed dentition. Am J Orthod Dentofacial Orthop 1997; 111: 321-327.

7. Husein J, Burden D, McSherry P. The Management of the palatally ectopic maxillary canine. London: Royal College of Surgeons of England; 2004.

8. Langberg B I, Peck S. Adequacy of maxillary dental arch width in patients with palatally displaced canines. Am J Orthod Dentofacial Orthop 2000; 118: 220-223.

9. Ericson S, Kurol J. Early treatment of palatally impacted maxillary erupting canines by extraction of the primary canines. Eur / Orthod 1988; 10: 283-29.

10. Power S M, Short M B. An investigation into the response of palatally displaced canines to the removal of deciduous canines and an assessment of factors contributing to favourable eruption. Br J Orthod 1993; 20: 215-223.

11. Baccetti T, Leonardi M, Armi P. A randomised clinical study of two interceptive approaches to palatally displaced canines. Eur J Orthod 2008; 30: 381-385.

12. Olive R J. Orthodontic treatment of palatally impacted maxillary canines. Aust Orthod 2002; 18: 64-70.

Evidence-Based Dentistry (2010) 11, 86-87. doi:10.1038/sj.ebd.6400742 